\title{
Presencia del Cancionero Popular Infantil en la literatura española de la Edad de Oro
}

\author{
Popular Children's Songs \\ in Spanish Literature of the Golden Age
}

\author{
Pedro Cerrillo Torremocha \\ Universidad de Castilla La Mancha
}

\section{RESUMEN}

Margit Frenk ha señalado coincidencias textuales entre canciones de tipo popular y 'tradicional', incluidas en obras literarias del XV al XVII, y ciertas canciones folclóricas vivas en nuestros días o que se pudieron recoger hasta hace pocos años. Esta afirmación nos animó a rastrear la presencia de canciones y retahílas de tradición infantil en obras de autores españoles del XVI y XVII: composiciones que, en ocasiones, provienen de la Edad Media y que, tras la invención de la imprenta, en algunos casos se fijaron por escrito y se incluyeron en obras literarias cultas. Hoy bastantes de esas composiciones están vivas en juegos y prácticas infantiles. Es un proceso de pervivencia en la memoria popular de la infancia. En este trabajo nos referimos a composiciones del Cancionero popular infantil y que aparecen, completas o en algunos de sus versos, en obras literarias del XVI y XVII, algunas de autores muy significativos.

Palabras Clave: lírica popular, Cancionero popular infantil, poesía.

\begin{abstract}
Margit Frenk pointed out the textual coincidences between popular and 'traditional' songs included in literary works from the $15^{\text {th }}$ to the $17^{\text {th }}$ Centuries and certain folk songs that have survived and are still used now or until quite recently. This encouraged the author of this paper to trace the utilization of traditional children's songs and verses in literary works by Spanish authors of the $16^{\text {th }}$ and $17^{\text {th }}$ Centuries. These compositions occasionally date from the Middle Ages and, with the invention of printing, were recorded in writing and incorporated into educated literary works. Many of these compositions can still be found in children's games and practices today. They have survived the passage of time though popular memory. This study looks at those popular children's songs which have been included, either entirely or in part, in the literary works of renowned authors of the $16^{\text {th }}$ and $17^{\text {th }}$ Centuries.
\end{abstract}

Key words: Popular Poetry, Children's Popular Songs, Poetry. 


\section{PRESENCIA DEL CANCIONERO POPULAR INFANTIL EN LA LITERATURA ESPAÑO- LA DE LA EDAD DE ORO}

Margit Frenk (2006: 125) ha señalado coincidencias textuales entre canciones de tipo popular y 'tradicional', que aparecen citadas o incluidas en obras literarias de los siglos XV a XVII, y ciertas canciones folclóricas que aún están vivas en nuestros días o que se pudieron recoger hasta hace no muchos años. Esta afirmación nos animó a rastrear la presencia de canciones, retahílas, cantilenas o sonsonetes de específica tradición infantil en obras literarias de autores españoles de los siglos XVI y XVII: son composiciones que, en ocasiones, provienen de la Edad Media y que, con la invención de la imprenta, en algunos casos se fijaron por escrito, llegando a aparecer en obras literarias cultas.

$\mathrm{Al}$ cabo de los siglos, los ecos de canciones que aparecieron documentadas en los registros escritos de la Edad Media, del renacimiento, del Barroco, han alcanzado a ser escuchados (y registrados, también) en el siglo XX, e incluso en el XXI, aun cuando, evidentemente, con un pulso cada vez menos audible. (Frenk y Pedrosa, 2008: 291).

Efectivamente, hoy —en muchos casos - y hasta hace pocos años - en otros- bastantes de esas composiciones se encuentran vivas en juegos y prácticas infantiles. Se trata de un proceso de pervivencia en la memoria popular. En este trabajo solo nos referimos a canciones o retahílas, con un apartado final para las adivinanzas, que aparecen, completas o en algunos de sus versos, en obras literarias escritas de los siglos XVI y XVII, algunas de ellas de autores muy significativos de nuestra historia literaria, pero que han permanecido vivas hasta nuestros días en la tradición popular infantil. Hace unos años, José Manuel Pedrosa (Vid. 2000) escribió sobre las «cancioncillas orales» en que se habían inspirado muchos de los mejores escritores españoles del Renacimiento y del Barroco.

El reconocimiento de una poesía lírica popular de tradición infantil ya no debe extrañar hoy, pese a los esforzados estudios que el previo reconocimiento de la existencia de una lírica popular ha necesitado, porque la crítica filológica asociaba poesía popular con épica, dejando de lado la poesía lírica. Fueron Dámaso Alonso y José M. Blecua quienes, refiriéndose al siglo XIX, siglo en el que se produce la recuperación y revalorización del folclore, afirmaron:

La crítica negaba la poesía lírica popular. La poesía popular era solo épica (canciones de gesta y romances); la lírica era siempre culta (...) Una serie de casualidades fueron descubriendo ante los ojos asombrados de Menéndez Pelayo la poesía de tipo tradicional, y con ella un tesoro de emociones fresquísimas, virginales... ¡Menéndez Pelayo acababa de comprender que sí, que existe la lírica popular! (Alonso y Blecua, 1978: 23).

Esa poesía lírica popular había tenido realizaciones más que notables en la Edad Media y se había proyectado con bastante fuerza en los siglos XVI y 
XVII, pero fue en el siglo XIX, con el trabajo de revalorización del folclore llevado a cabo por los románticos cuando empezó a extenderse esta rama de la literatura con un poco de rigor, llevando a cabo la fijación escrita de una literatura que se había desarrollado antes de la invención de la imprenta y que estaba viva en la tradición de la literatura oral.

Demófilo (Antonio Machado y Álvarez) cita nominalmente a algunos de los primeros recolectores de canciones de mediados del siglo XIX: Fernán Caballero, Lafuente Alcántara, incluso se refiere a García Gutiérrez quien, en 1862, dedicó su discurso de recepción en la Academia Española de la Lengua a los cantares populares, aunque un poco antes, a principios de aquel siglo, hubo otros autores que recogieron coplas y canciones:

Ya por los años de 1805, 1807 y 1825, un señor Zamacola, escribano conocido con el renombre de Don Preciso, y otros dos autores, que ni aún el trabajo se tomaron de legar sus nombres a la posteridad (...), se dieron al entretenimiento de coleccionar coplas y seguidillas, trovos, polos y tiranas. (Demófilo, 1883: 146).

Se iniciaba así un proceso de afirmación de la poesía lírica popular que, a diferencia de la culta, era: «espontánea, desinteresada y, por lo tanto, menos reflexiva, menos artificiosa y expuesta a ser influida por condiciones de edad, sexo, clima, etc.» (Demófilo, 1883: 159).

Esa poesía lírica popular ha sido cultivada universalmente, con mecanismos de transmisión y perpetuación prácticamente iguales en todos los casos. La universalidad de esa tradición popular no está en los hechos que contempla, ni tampoco en las formas con que se expresa; su universalidad es una consecuencia de los sentimientos que mueven la propia tradición, del espíritu o las creencias que la conforman y de la manera en que se interpreta el mundo, que no es la misma que la de la cultura letrada.

\section{Sobre El CARÁCTER Literario DEl CANCIONERo Popular INFANTIL}

Aunque siempre, lógicamente, han existido niños, no siempre han sido considerados, socialmente, de la misma manera. Es radicalmente distinto el concepto que, actualmente, se tiene de infancia, así como de su tratamiento, que el que se tenía en la Edad Media, en donde no había consciencia de que los niños fuesen distintos de los adultos; en tal situación, está claro que la sociedad no se podía estructurar en torno al niño, y este debía aprender en idénticas condiciones que el adulto, compartiendo también, por tanto, la literatura. El concepto de infancia como un estadio propio surge con la aparición histórica de la burguesía que quiso dar al niño un espacio autónomo en donde fuera posible preservar su inocencia: era un modelo idealizado que se alejaba mucho de la realidad de la infancia. 
La aceptación de la infancia como etapa previa y distinta del mundo adulto y el interés que despertó el folclore en el siglo XIX fueron muy importantes para la poesía lírica popular infantil (a la que nos referimos también como Cancionero Popular Infantil), porque se empezaron a recoger y a fijar literariamente composiciones que estaban vivas en la oralidad, por un lado, y porque con ello se empezaron a definir las bases que permitirán caracterizar, posteriormente, la Literatura Infantil.

En estudios anteriores ${ }^{1}$, además de proponer una clasificación del Cancionero Popular Infantil por tipos de composiciones, hicimos una pormenorizada caracterización literaria de la poesía lírica popular de tradición infantil, en la que son especialmente relevantes tanto el ritmo que, en buena medida, es fruto del uso reiterado de paralelismos, estribillos, sinsentidos, procedimientos repetitivos de diverso tipo, como ciertas convenciones retóricas de carácter general: metáforas, comparaciones, hipérboles, personificaciones o juegos de palabras, que adquieren significado propio en este tipo de composiciones. Además, el análisis de la organización interna de estas composiciones aporta elementos muy singulares, como el uso acusado de fórmulas que se repiten para iniciar o concluir la cantilena o la frecuencia con que aparecen estructuras basadas en la repetición de elementos (por enumeración o por encadenamiento, sobre todo).

Es preciso recordar que en el proceso de perpetuación oral de una obra literaria no solo intervienen el emisor y el destinatario; aun siendo imprescindible su participación, la comunidad en que esa obra se ejecuta, va a ser la que haga posible, finalmente, su perpetuación o su desaparición, con su aceptación o con su rechazo. Jakobson (1973: 60) lo explica así:

\begin{abstract}
L'existence d'une oeuvre folklorique ne commence qué après son acceptation par une communauté dèterminée, et il n'en existe que ce que la communauté s'est approprié. Supposons qu'un membre d'une communauté ait compose une oeuvre personelle. Si cette oeuvre orale se révèlait, pour la communauté, sin tous les autres membres de la communauté no se l'appropriaient pas, elle serait vouée à disparaître. Seule, la transcription fortuite d'un compilateur peut la sauver, en la faisant passer du domaine de la poésie orale à celui de la littérature.
\end{abstract}

Pues bien, los niños han intervenido en esa aceptación y perpetuación de la obra folklórica, y lo han hecho no solo como componentes de la comunidad a la que pertenecen, sino también como colectivo con intereses, prácticas y gustos propios. Así, con el tiempo, los niños han ido practicando toda una serie de composiciones, de distinto tema y tono, hasta el punto de que se convirtieron en composiciones de tradición específicamente infantil, bien porque solo ellos eran los destinatarios de las mismas (canciones de cuna o juegos mímicos de la primera infancia), bien porque aplicaron las retahílas o

\footnotetext{
${ }^{1}$ Pedro Cerrillo (1994 y 2005).
} 
canciones a usos muy concretos de los que el adulto quedó enseguida al margen (fórmulas para echar a suertes, canciones escenificadas, oraciones, etc.) Así lo entiende Margit Frenk (Vid. 1978: 25-26) cuando, al referirse a los temas de la lírica española de tipo popular, cita las «rimas infantiles» como un grupo temático «curioso», pero recogiéndolo en apartado diferenciado.

Sin duda, la intervención de la infancia en el proceso de transmisión oral es importante, al tiempo que ofrece características propias de un momento cronológico identificable en otros muchos aspectos:

Los niños conservan 'inconscientemente' en sus juegos el recuerdo de lo que fue, $\mathrm{y}$, poniendo su memoria y su poderoso instinto de imitación al servicio de estas aparentes bagatelas, perpetúan los testimonios de monumentos realmente primitivos de la humanidad... (Demófilo, 1883: 180).

\section{CANCIONES INFANTILES ASOCIADAS A JUEGOS, BAILES Y ENTREMESES EN LA EDAD DE ORO}

Sabido es que la tradición del Cancionero Popular Infantil ha bebido en las fuentes del romancero pero también se pueden percibir ciertas presencias de elementos de ese cancionero en obras de escritores cultos, quienes se sirvieron de composiciones que forman parte del Cancionero Popular Infantil para enriquecer sus textos, en la línea del uso que también hicieron, sobre todo en el teatro barroco, de composiciones populares de tradición general, probablemente con el fin de provocar una cercanía más inmediata con el público. El ejemplo más significativo son, probablemente, las canciones escenificadas, composiciones que van, necesariamente, acompañadas de una acción que, en unos casos, se representa (incluso con papeles asumidos por los participantes en ella) y que, en otros, se mima solamente. Da igual que sean interpretadas a la rueda, a la comba, en filas, en grupo o al columpio; da igual que se trate de actuaciones muy concretas (la dola, el burro, el moscardón); incluso algunas de ellas, en ciertos casos, se interpretan de modos distintos, según sea su localización geográfica ${ }^{2}$. De todos modos, la característica principal de estas canciones es su utilización en diferentes actividades grupales, esencialmente lúdicas, que requieren determinados movimientos y gestos; en ese sentido,

${ }^{2} \mathrm{El}$ estudio literario de las canciones escenificadas plantea un problema ya en su inicio: el que representa la fijación de sus límites y la terminología que emplearemos para su designación. En las antologías y cancioneros existentes podemos encontrarlas agrupadas o diferenciadas en «canciones de comba», «de rueda», «de corro», «de filas», «de columpio», «de grupos», (...) En otras ocasiones se las conoce con el término más general de «canciones infantiles». Pese a los inconvenientes que conlleva su fijación y su delimitación, parece conveniente realizar un esfuerzo en tal sentido, de modo que se evite su posible confusión con otros tipos de composiciones y que, al mismo tiempo, se logre la mayor aproximación a su definición y, con ella, a su caracterización. (Cerrillo, 2004). 
podríamos considerarlas como el «soporte literario» de esas actividades. Las acciones que dan lugar a los juegos a que acompañan las canciones escenificadas requieren siempre palabras y gestos para su correcta interpretación; son juegos muy diversos que se podrían agrupar en dos grandes bloques: los juegos masculinos (dola, burro, pídola, clavo, moscardón), que exigían un esfuerzo mayor y, en algunas ocasiones, podían provocar cierto daño, y los juegos femeninos (corro, comba, columpio, filas), que requerían más habilidad en la mayoría de los casos, aunque algunos de los juegos se interpretaban tanto por chicos como por chicas (pelota, por ejemplo).

Rodrigo Caro (en Días geniales o lúdricos, escrito hacia 1626, aunque editado por primera vez en 1884) relacionaba las prácticas de ciertos juegos que iban acompañados de canciones o retahílas, con los estamentos sociales más populares, aunque también se refiere a la presencia de «corros» en el Antiguo Testamento (Vid. Caro, 1978: 58-63). De la antigüedad de estas fórmulas el libro de Caro, ya en la primera mitad del siglo XVII, informa cumplidamente, al tiempo que describe de manera pormenorizada juegos infantiles que se practicaban en aquellos tiempos y que se acompañaban de retahílas que los chicos recitaban ritualmente en la ejecución de los mismos. Elementos del juego o, incluso, de la retahíla los encontramos en juegos actuales de ejecución parecida; veamos un ejemplo:

(...) A ese juego le llaman: sal, salero. Es así: pónese una rueda de muchachos y uno en medio; éste dice en alta voz, teniendo cerrados los ojos y andando a la redonda: 'zarzabuca, de rabo de cuca, de cucandar, que ni sabe arar ni pan comer, vete a esconder detrás de la puerta de San Miguel'. Donde para decir esto, aquel muchacho sale y se va a esconder, y así va repitiendo las mismas palabras y echando fuera muchachos hasta que se han ido todos. Después los sale a buscar diciendo: 'Sal salero, vendrás caballero en la mula de Pedro'. Ellos procuran salir de donde están y llegar primero al puesto, porque al que puede coger le hace que lo traiga a cuestas. Éste es el juego cumplidamente. (Caro, 1978: 134).

En este juego podemos intuir elementos propios de juegos infantiles actuales, como «el escondite» o «el moscardón». Debió de ser un juego muy difundido entonces, pues en la colección de juegos del siglo XVI encontrados por Rodríguez Marín en «Memorial de un pleito», última parte del libro Sales españolas, o agudeza de ingenio nacional ${ }^{3}$, aparece como uno de los 38 juegos de la colección el llamado «Sansobuque, de rabo de cuque», que es fácilmente identificable con el «Sarabuca» de Caro (Vid. Rodríguez Marín, 1932: 10-11).

Por su parte, Fernando Llorca (1998: 132-133), ya en el siglo XX —en 1914_, recogió esa composición, con muy pequeñas diferencias:

${ }^{3}$ Editado por Antonio Paz y Meliá, jefe del departamento de manuscritos de la Biblioteca Nacional de Madrid, como tomo LXXX de la colección de «Escritores castellanos». 


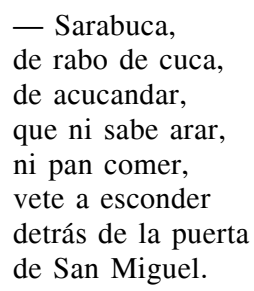

Ochenta años después que Llorca, nosotros pudimos recoger una cantilena que también contiene elementos presentes en aquella de Caro:

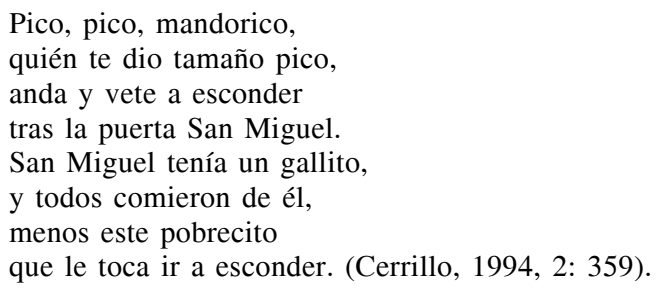

Son bastantes las canciones escenificadas que aparecen en la literatura culta española de los siglos XVI y XVII, incluidas en bailes y entremeses, aunque entonces, quizá, no pertenecían todavía a una tradición exclusivamente infantil; fue con el paso del tiempo cuando se fueron incorporando al acervo específicamente infantil, pues se empleaban solamente en los juegos de los niños.

Un ejemplo muy interesante sería el de «Hilo de oro» (Vid. Cerrillo, 2004: 182-186), canción que trata un tema recurrente en el Romancero, el de la elección amorosa, y que pervive como canción escenificada infantil tanto en España como en Latinoamérica, en diferentes versiones que afectan, incluso, a su verso inicial: «A la cinta, cinta de oro», «Anillito de oro», «Piso oro, piso plata», «Cordoncito de oro», «De Francia vengo, señores», «De Francia vengo, señora». Rodríguez Marín (1932: 55) afirmó que el romance ya era conocido en el siglo XVI y que en el XVII se representaba como juego. Margit Frenk (1987: 1031-1032) recoge una versión de la que dice que su fuente es un baile anónimo, Baile curioso de Pedro de Brea (1616): en la acotación previa al baile se dice: «Salen los músicos con sus guitarras y algunas damas con ellos, divídanse en dos corros y siéntanse diciendo (...)» (Cotarelo, 1911: 479b); y en el desarrollo del propio baile, podemos leer versos como estos, de fácil identificación en cualquiera de las versiones que se conservan vivas:

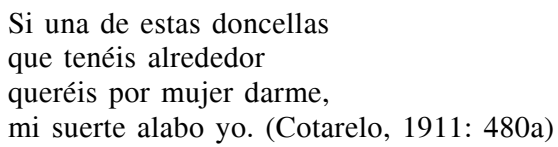

O como estos otros: 


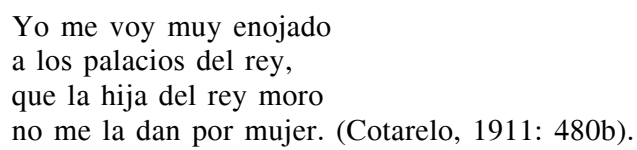

Por su parte, Ana Pelegrín (1996: 272-273) dice que en el XVII lo mencionaron también Lope de Vega y Tirso de Molina, lo que pudiera entenderse como un claro indicio de que era conocido popularmente ya entonces. De todos modos, será en el siglo XIX cuando empiecen a aparecer las primeras versiones completas fijadas por escrito; veamos la que se guarda en el Archivo del Seminario Menéndez Pidal ${ }^{4}$, recogida en 1929 en Alcolea del Río (Sevilla) por Eduardo Torner:

- De Francia vengo, señora me han dicho en el camino

5

15
Que las tenga o no las tenga con un pan que Dios me ha dado - A Francia vuelvo señora que las hijas del rey moro. - Vuelva, vuelva caballero de las tres hijas que tengo - Esta tomo por esposa que ha parecido una rosa - Lo que tengo que rogarle

- Bien tratadita estará sentada en silla de plata azotitos con correas $y$ una perita en la boca traigo un hijo portugués que lindas hijas tenéis. yo las sabré mantener otro que lo ganaré. a los palacios del rey no me las dejaron ver. no sea tan descortés, tome la que gusté usté. ésta tomo por mujer me ha parecido un clavel. es que me la trate bien. y bien comida también, bordando encajes al rey cuando sea menester 30 a las horas de comer.

Es una versión de treinta versos en los que se establece un diálogo entre un caballero y la madre de las hijas del rey moro; el caballero que, de oídas, tiene muy buenas referencias, pretende a una de las hijas. Tras una primera negativa de la madre (probablemente se trata de una convención propia de la primera petición) y ante la decisión del caballero de no insistir (en forma de reacción airada, quizá también convencional), la madre reconsidera su respuesta y le dice que elija entre las tres hijas: el caballero elige y, a partir de ese momento, el diálogo trata del cuidado que le dispensará a la muchacha.

Rodríguez Marín (1932: 56) describe así el juego:

Colócanse varias niñas en hilera, sentadas en el suelo, cada una entre las piernas de la anterior, a la que vuelve, naturalmente, la espalda; la última de la fila hace el papel de madre, y las demás son sus hijas. Así colocadas, llega un niño o niña, que hace de embajador [caballero], entre el cual y la madre se entabla el diálogo siguiente (...).

En su práctica como canción escenificada infantil, es un juego dialogado, repetitivo, de elección y, por tanto, de eliminación, por el que las niñas in-

\footnotetext{
${ }^{4}$ Pelegrín (1996: 274).
} 
tervinientes que van asumiendo, sucesivamente, el papel de hija elegida por el caballero, van siendo eliminadas. En el Cancionero Popular Infantil son frecuentes las canciones escenificadas que conllevan una elección, muchas de las cuales siguen siendo interpretadas por las niñas como «corros», «filas»o «combas»: «La jardinera», «La viudita del Conde Laurel», «Arroz con leche», «Al olivo subí», «Estaba una pastora», «La carbonerita», etc.

Algunas de las singularidades más llamativas de ese proceso de apropiación de ciertas composiciones (sobre todo romances) por parte de los niños son: la tendencia a la fragmentación de la composición original, el intercalado de estribillos que faciliten la memorización y una cierta contaminación con elementos extraños a la historia original, que pueden llegar a provocar ciertas deformaciones expresivas y algunos sinsentidos. Fijémonos en algunos ejemplos:

Los dos primeros versos de la versión de Torner, antes citada, dicen:

De Francia vengo, señora, traigo un hijo portugués (...).

En otra versión, citada por Pelegrín (1996: 199-200), se dice:

De Francia vengo, señores, de por hilo portugués (...).

Parecería más lógico que fuera «hilo» y no «hijo»: tiene sentido «hilo portugués», ya que era un hilo muy valorado y reconocido en el siglo XVII. Pero la deformación es más llamativa en otros casos, en los que llegan a aparecer expresiones sin un significado lógico, como en esta versión de El Ballestero (Albacete), recopilada en 1983 por Concepción Vázquez (Vid. Fraile, 1993: 51):

De Francia vengo, señores, un poquito por su bien (...).

También es una versión notablemente contaminada la que recogen Raquel Calvo y Raquel Pérez, sobre todo en las explicaciones que el caballero da para elegir a una de las hijas y no a las otras (versos 17 a 23), que es, además, la parte en que se abandona el octosílabo, mantenido hasta ese momento regularmente:

A la cinta, cinta de oro, en el camino me han dicho:

$5-$ Que las tenga o no las tenga,

- Yo me voy muy enojado a contárselo a la reina que las hijas del rey moro ni por oro, ni por plata, a la hoja de laurel,

— ¡Qué buenas hijas tié usted! ¡qué se le importará a usted! a los palacios del rey 10 y a la infanta doña Inés, no me las quieren vender ni por punta de alfiler, 
ni por dinero que valga

- Ésta no la quiero

a ésta me la llevo

parece una rosa,

acabado de nacer.

25 que me la cuide usted bien.

sentadita en silla de oro

con la manzana en la boca la corona de Isabel. porque es pelona, 20 por linda y hermosa; parece un clavel - Lo que le encargo, caballero, - Bien cuidadita estará, bordando paños al rey, a la hora de comer.

(Calvo y Pérez, 2003:88).

Cotarelo habla de otras «tonadillas» que se incluían, intercaladas, en entremeses y bailes, y cita una que encontró en el entremés Los niños fingidos, de principios del XVIII y atribuido al Marqués de Olmeda, de la que, probablemente, debió existir alguna versión en el siglo anterior:

Y así cada cual su niño con un tonillo arrullemos del Serení, que es el aria que gusta a mis mosqueteros. (Cotarelo, 1911: CCLXXXVIII).

En esa tonadilla podemos percibir reminiscencias del género de las canciones de cuna («arrullemos») y la presencia de un personaje que aparece en una canción escenificada infantil:

San Serení del monte, san serení cortés, yo, como buen cristiano, yo me arrodillaré (...) (Cerrillo, 1994, II: 318).

Pedro M. Piñero (2010: 336) se ha referido a la presencia del estribillo «ro, ro, ro» en canciones de finales del siglo XV o principios del XVI, y cita expresamente una nana de la Comedia de Rubena, de Gil Vicente:

$\mathrm{Ru}, \mathrm{ru}$, menina, ru, ru!

Mouram as velhas e fiques tu, coa tranca no $\mathrm{cu}^{5}$.

Mariana Masera (1994: 199-219) y el propio Piñero (2010: 336) citan también la presencia de otro estribillo muy frecuente en las nanas hispánicas («ea»), junto al conocido personaje del «coco», en otra obra culta, el Auto de los desposorios de la Virgen, de Juan de Cajés:

Ea, niña de mis ojos,

duerma y sosiegue,

que a la fe que venga el coco

si no se duerme 6 .

\footnotetext{
${ }^{5}$ Recogida por Frenk (2003), con el número 2048.

${ }^{6}$ Frenk (2003: 2047 ter).
} 


\section{El insólito CASO DE AlONSO DE LEDESMA}

Si la literatura culta ha usado composiciones del Cancionero Popular Infantil es porque los autores se encontraban ante composiciones de notable popularidad que les servían, en determinados contextos, para la difusión de sus propios escritos. En este sentido, Alonso de Ledesma (1613) recogió casi una colección completa de juegos que se ejecutaban —algunos aún se ejecutan- acompañados de cantilenas: «Tira y afloja», «Salta tú y dámela tú», «Para, para», «El escondite», o uno en el que un muchacho, vuelto de espaldas a los demás tiene que soportar un golpe y acertar quién se lo ha dado, a no ser que quiera seguir recibiendo más golpes (acción que ha pervivido como juego de chicos, «El moscardón»), y que Ledesma utiliza para componer unas redondillas dedicadas a «La bofetada de Cristo y negación de San Pedro»:

Adivina quién te dio,

que la mano te asentó. (Alonso de Ledesma, 1613: f. 1).

Lo más sorprendente del libro de Alonso de Ledesma podemos intuirlo ya en su título completo, Juegos de Nochesbuena a lo divino moralizados a la vida de Cristo, martirio de Santo, y reformación de costumbres. Con unas enigmas hechas para honesta recreación, y en su elocuente dedicatoria, «Dirigido a la serenísima Virgen María Reyna de los Ángeles y Señora nuestra». Efectivamente, él no quiere dirigirse a los niños, aunque se sirva de composiciones que solo ellos usan; incluso, por si hubiera dudas, lo explicita en el prólogo advirtiendo al lector que su intención es: «Servirte y recrearte, juntando lo dulce con lo provechoso: solo te ruego no lo tomes como juego de niños, pues en ellos te digo lo que te importa».

Y advierte que si algunas composiciones las «juegan» los niños, el lector no debe prestar atención a la forma del juego sino al entendimiento de la «letra». La advertencia es fácilmente comprensible cuando comprobamos que Alonso de Ledesma se sirve de expresiones o retahílas propias de determinados juegos infantiles para lograr una mejor comunicación del contenido de sus textos religiosos. Así, incluye la retahíla de la suerte infantil «Pares o nones» (Vid. Rodríguez Marín, 1981, I: 134), que ya debía ser conocida en aquellos años como fórmula de sorteo para ciertos juegos infantiles, en el extenso «El juego de que me lo dizes, pares o nones. (A la Santísima Trinidad, romance)»:

La republica del hombre

$\mathrm{Fe}$, Esperança y Caridad,

Entendimiento y Memoria

y la libre Voluntad.

Quieren hazer noche buena,

cinco damas y un galán,

por entretener al huésped,

que en casa del alma está. 


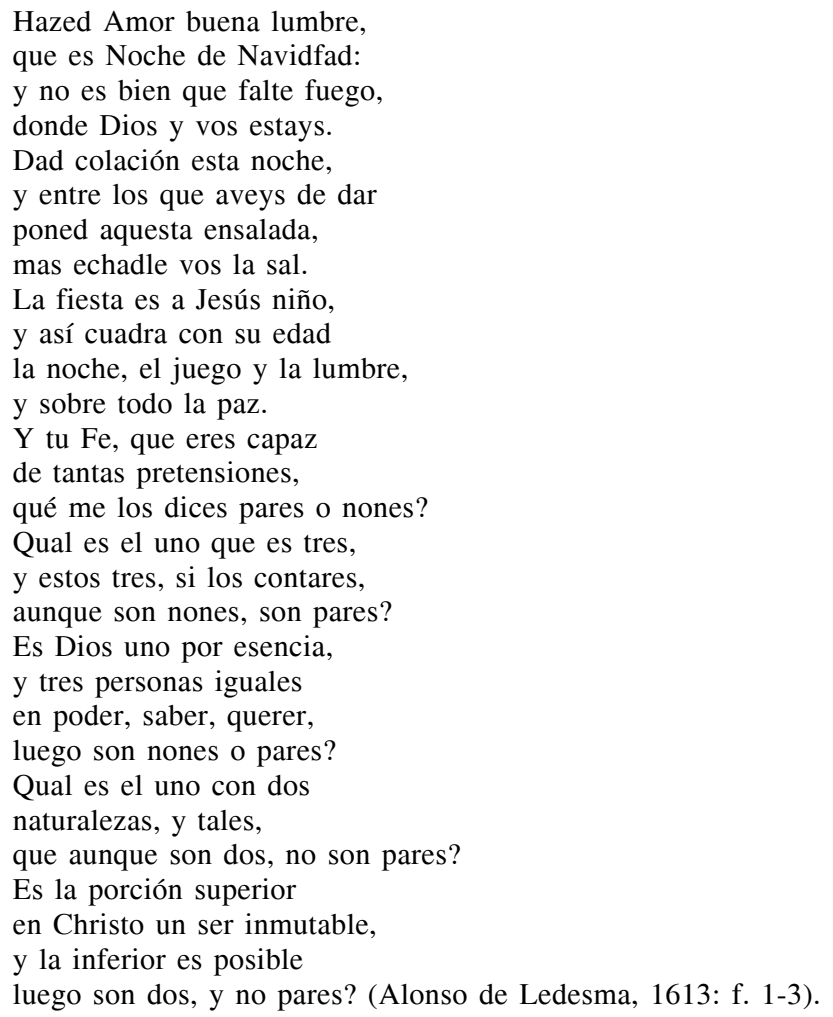

Algo parecido encontramos en otros de estos juegos «a lo divino» de Alonso de Ledesma, de los que citaré los siguientes: «la pájara pinta», que es motivo para sus redondillas al Espíritu Santo; «a la lima, a la limón», que aparece en las redondillas en las que se refiere a la «cuenta que ha de pedir Dios en el juicio final»; «caracol, caracol, saca tus hijuelos al rayo del sol» en el romance «al mal estado de un pecador»; o «La gallina ciega» en las décimas a «Santa Lucía, Virgen y mártir» (Alonso de Ledesma, 1613: 31-32, 72-74, 99-101, y 101-102).

\section{AlgunOS EJEMPlos MÁS}

Sousa Viterbo (1901: 9) incluye, igualmente, algunos juegos en su colección, aludiendo además a otra, la de Lorenzo Spirito (1515). Algunos pequeños juegos ofrecen también el Cancionero General (1550) y el Cancionero llamado flor de enamorados (1562) de Juan de Timoneda, así como Prendas de amor (1588) de Lope de Rueda o El cortesano de Luis de Milán (¿1561?, Vid. 1874). Este último incluye en su libro la siguiente cancioncilla que, de nue- 
vo, podemos asociarla al citado juego del «moscardón» (véase la semejanza entre «abejón» y «moscardón»), un juego de chicos que Milán indica que, entonces, era un «juego de milicia»:

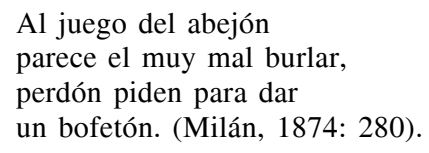

El origen remoto de la conocida canción «A la lima, a la limón» podríamos encontrarlo en una canción que recogió Miguel Sánchez en un «Baile de maya» ${ }^{7}$ :

- Ora lirón, lirón,

¿de dónde venís de andare?

- Ora lirón, lirón,

de San Pedro el Altare.

- Ora lirón, lirón, ¿qué os dijo don Roldane?

- Ora lirón, lirón, que no debéis de pasare.

- Ora lirón, lirón, quebradas son las puentes.

- Ora lirón, lirón, mandadla adobare.

- Ora lirón, lirón, no tenemos dineros.

- Ora lirón, lirón, nosotros los daremos.

- Ora lirón, lirón, ¿de qué son los dineros?

- Ora lirón, lirón, de cáscaras de huevoi.

- Ora lirón, lirón, ¿en qué los contaremos?

- Ora lirón, lirón, en tablas y tableros.

- Ora lirón, lirón, ¿qué nos daréis en precio? - Ora lirón, lirón, un amor verdadero.

Correas (1627: 271) recogió un sonsonete, en tono de burla, que hoy conservamos, en diversas variantes, como burla o, también, como juego mímico ${ }^{8}$ :

\footnotetext{
${ }^{7}$ Miguel Sánchez (1616). Comedias. Madrid. Cit. Por Frenk (2003: 1277).

8 «Sana, sana, /culito de rana; / si no sanas hoy, / sanarás mañana». (Cerrillo, 1994, II: 256).
} 


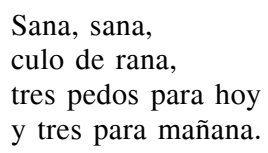

Mariana Masera (2010: 95) refiere la presencia de elementos de la canción «Estaba la Pájara Pinta» en Metodo mui facilísimo para aprender a tañer la guitarra, un libro de Luis Briceño editado en 1626:

\author{
Bolava la palomita \\ por encima del verde limón, \\ con las alas aparta las ramas, \\ con el pico lleva la flor.
}

\title{
LA ADIVINANZA EN LA LITERATURA ESPAÑOLA RENACENTISTA Y BARROCA
}

No podemos considerar la adivinanza un género de exclusiva tradición infantil, incluso, en su origen, no era un género especialmente destinado a la infancia; sin embargo, sí es cierto que los niños, con su continua práctica y frecuente recreación, han sido quienes mejor han contribuido a la vital pervivencia de esta composición.

En la literatura clásica, así como en las literaturas cultas occidentales, muchos libros contienen ejemplos de adivinanzas, o de construcciones similares a la adivinanza. Tenemos constancia de la existencia de enigmas y acertijos en la literatura griega (su práctica era un entretenimiento literario de eruditos y hombres cultos en general, siendo frecuentes las competiciones en las que se dirimía la capacidad y la sabiduría de los contendientes en la resolución de los acertijos planteados); también en las culturas orientales eran conocidos los enigmas (Pantschatantra): «Los antiguos reyes de Egipto y Babilonia eran tan aficionados a los acertijos, que se los enviaban recíprocamente, por medio de emisarios, de una corte a otra, de manera que aquel que no los acertaba tenía que pagar al otro un tributo determinado» (Gárfer y Fernández, 2010: 15).

Sin embargo, en la literatura latina parece ser que los enigmas no estuvieron muy presentes. Los menciona Aulo Gelio; Petronio, por su parte, hace imprecisas referencias a algunos enigmas de carácter popular. Celio Firminiano Simposio recogió una colección de casi cien adivinanzas sobre objetos diversos, y hay algún testimonio escritos de Quintiliano en el que afirma que Virgilio y Cicerón fueron aficionados a la resolución de acertijos.

La literatura culta española, en no pocas ocasiones, ha usado la adivinanza popular, bien repitiéndola con exactitud, bien, sobre todo, añadiéndole otros elementos literarios, al tiempo que ha propiciado la aparición de nuevas adivinanzas, de exclusivo origen culto que, en general, se diferencian de las populares por ser más extensas y más complejas significativamente. 
Ya en la Edad Media, en la tradición de la adivinanza se unieron fuentes diversas, también las cultas y las populares, de lo que las sociedades con lenguas románicas se favorecieron. En muchas ocasiones, las adivinanzas que forman parte de textos cultos tienen un componente significativo extremadamente complejo, con elementos eruditos, incluso. Es el caso, insólito para quien lo desconozca, de las adivinanzas contenidas en el Libro de Apolonio, uno de los mejores exponentes anónimos del Mester de Clerecía del siglo XIII. Ese libro, compuesto hacia el año 1240, ofrece las más antiguas adivinanzas españolas cultas de cuya constancia escrita tenemos noticia; veamos una de ellas:

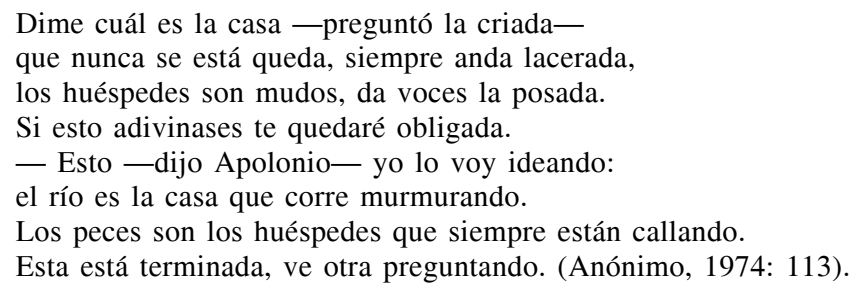

No es frecuente encontrarnos con adivinanzas, ni con otros tipos de poesía lírica, compuestos en la forma métrica de la cuaderna vía, ni es frecuente que las adivinanzas se expresen en un lenguaje tan elaborado como el del ejemplo expuesto. De modo parecido, en el Libro de Apolonio se suceden diversas adivinanzas para «las naves», «el ancla», «la esponja», «las ruedas» o «el espejo».

También en el Conde Lucanor de Don Juan Manuel, o en obras del Arcipreste de Hita, Marqués de Santillana y Juan de Mena, o en textos de autores representados en diversos cancioneros cortesanos del siglo XV (Cancionero de Baena o Cancionero de Stúñiga) podemos encontrar, a veces con gran sorpresa, elaborados exponentes de adivinanzas cultas, aunque se percibe en casi todas ellas, de gran extensión, el juego dialógico de ingenio del que son portadoras. En el Cancionero de Baena (recogido por Juan Alfonso de Baena entre 1430 y 1440, aunque publicado por vez primera en 1851), Alfonso Álvarez de Villasandino incluye, entre otras, esta adivinanza para «Las nubes»:

$$
\begin{aligned}
& \text { Hermanas somos llamadas } \\
& \text { y en uno nos juntamos, } \\
& \text { y más de cien jornadas } \\
& \text { unas de otras estamos; } \\
& \text { las gentes son despegadas } \\
& \text { donde mucho porfiamos; } \\
& \text { otro tiempo son cuitadas } \\
& \text { porque no las visitamos }
\end{aligned}
$$

\footnotetext{
${ }^{9}$ Vid. Obras en metro de diversos poetas recopiladas por Baena. En: www.cervantesvirtual.com/ servlet/SirbeObras/01394953177137539314802/index.htm (consultado el 5 de diciembre de 2010), f. $43 \mathrm{v}$.
} 
Casi en el tránsito de la Edad Media a la Edad de Oro, Antonio de Nebrija, en su Gramática Castellana (1946: 133) se refirió al enigma como aquello que se produce «Cuando dezimos alguna setencia escura por escura semejança de cosas, como el que dixo:

La madre puede nacer

de la hija ya difunta.

Se estaba refiriendo, como él mismo explicó al «agua que se engendra de la nieve $\mathrm{i}$ despues en torno de la nieve el agua».

En algunas obras de escritores cultos ya de principios del siglo XVI, como el profesor salmantino Fernando de la Torre, (Vid. Díez, 1983: 238-239) podemos encontrar fórmulas de inicio propias de la adivinanza, como el «qué cosa es cosa», con diversas variantes, fórmula que también aparece en obras de Cristóbal Mosquera de Figueroa (1955) o Sebastián de Horozco (1975).

Mosquera de Figueroa (1955: 40), en el poema «Loor de la Santísima Cruz», introduce la fórmula «qué es cosa y cosa». Por su parte, Sebastián de Horozco (1975: 221 y 236), en el poema 339 de su Cancionero incluye una pregunta hecha a una dama llamada Romana, cuyos primeros versos dicen así:

Di, Romana,

¿esto qué es cosi cosa?

Y en la composición 363:

¿Qué es cosi, cosa, dezid, el sol nacer de una estrella, y ella del, antes que el della?

También incluye Orozco una extensa adivinanza para «la hormiga» ${ }^{10}$ :

¿Qué cosa es aquélla o cuál
que por su mal
le nace lo que no tiene
y con esto es hecho igual
al animal
que en los aires se mantiene?
Vive de ajeno sudor
y sin temor
hurta lo que bien le plaze
y naide, que es lo mejor,
ha dolor
del gasto que ésta le hace.

Muy interesante son las Trescientas preguntas de cosas naturales con sus respuestas, de Alonso López de Corella (Valladolid, 1546), todas ellas referidas a las ciencias naturales. Pero también Juan del Enzina, Tomás de Mer-

\footnotetext{
${ }^{10}$ Gárfer y Fernández, 2000: 70.
} 
cado, Lope de Vega, algunos escritores ascéticos y místicos, Cervantes, Francisco de Quevedo, Agustín de Rojas o Luis de Góngora, entre otros, nos ofrecen ejemplos de adivinanzas en algunos de sus libros, tratándose casi siempre de adivinanzas cultas.

Cervantes, en el Libro VI de La Galatea (Madrid, 1584), hace jugar a las adivinanzas a sus pastores, cuando Aurelio propone: «...que cada cual, como mejor supiere, muestre aquí la agudez de su ingenio, proponiendo alguna pregunta o enigma a quien esté obligado a responder el compañero que a su lado estuviere». (1986: 907)

El propio Aurelio es quien inicia el juego con esta larga y culta adivinanza, tras la que se esconde el «vino»:

¿Cuál es aquel poderoso que desde Oriente a Occidente es conocido y famoso? A veces fuerte y valiente; otras flaco y temeroso; quita y pone la salud, muestra y cubre la virtud en mucho más de una vez, es más fuerte en la vejez que en la alegre juventud. Múdase en quien no se muda por extraña preeminencia; hace temblar al que suda, y a la más rara elocuencia suele tornar torpe y muda; con diferentes medidas anchas, cortas y extendidas, mide su ser y su nombre, y suele tomar renombre de mil tierras conocidas. Sin armas vence al armado, y es forzoso que le venza, $\mathrm{y}$, aquel que más le ha tratado, mostrando tener vergüenza, es el más desvergonzado, y es cosa de maravilla que, en el campo y en la villa, a capitán de tal prueba cualquier hombre se le atreva, aunque pierda en la rencilla. (Cervantes, 1986: 907).

También, en otro momento de La Galatea, Cervantes (1986: 759) escribe:

Pero sea o no sea nada,

Decidme, qué es cosa y cosa.

Cristóbal Pérez de Herrera, escritor que vivió entre 1558 y 1620 , en sus 
Proverbios morales y consejos cristianos, muy provechosos para concierto y espejo de vida, adornado de lugares y textos de las divinas y humanas letras. 311 enigmas philosóphicas, naturales y morales, con sus comentos (1618: 165), incluye este enigma/adivinanza para «el lobo»:

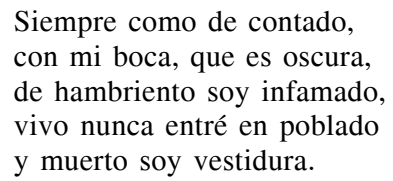

Y esta otra adivinanza para «el árbol», de la que aún perviven algunas variantes:

Quién es un viejo ligero,

que es de quattro movimientos

puestos en doce cimientos. (Pérez de Herrera, 1618: 19).

También hay adivinanzas cultas en el ya citado Cancionero llamado flor de enamorados de Juan de Timoneda (1562, Vid. 1954: XXVII) o en la Diana enamorada de Gil Polo (1564, Vid. 1973). Margit Frenk, con su proverbial tino filológico, recoge en su Nuevo Corpus (2003: 211), entre otras adivinanzas, tres que incluyeron en sus obras Juan de Mal Lara, Lope de Vega y Gonzalo Correas. El primero, en su La Philosophia vulgar... (Sevilla, 1568), refiere una adivinanza para «ojo» que, según afirma, debía ser de uso infantil, ya que los niños la decían a los baúles o arcas donde guardaban sus juguetes:

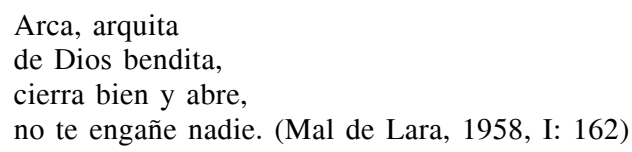

Lope de Vega, por su parte, en Con su pan se lo coma, escribe esta adivinanza para «la bellota»:

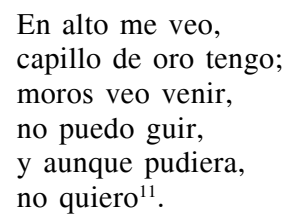

El propio Lope, en Los pastores de Belén (1612), que escribe para su hijo Carlos Félix, pone en boca de los pastores que van al Portal de Belén, adivi-

\footnotetext{
${ }^{11} \mathrm{http} / / / \mathrm{www} . c e r v a n t e s v i r t u a l . c o m / o b r a / c o n-s u-p a n-s e-l o-c o m a-0 /$ [Consultado $13 \mathrm{de}$ enero de 2011]
} 
nanzas como esta para «la castaña» (que también ofrece en La Arcadia), muy extensa y en versos de arte mayor, salvo el $5^{\circ}$ :

Decid, pastores, ¿cómo se apellida aquella que entre montes fue nacida, con siete letras entre espinas fieras, de la cual, si quitáis las dos postreras, en mil no hallaréis una:

tanto se estima cuando se halla alguna? (Lope de Vega, 1991: 214).

Gonzalo Correas, en su Arte de la lengua española, ofrece una compleja adivinanza para «el candil»:

Cuelgan al vivo, porque es menester; todos los muertos le vienen a ver; del grande placer que el vivo ha tomado, todos los muertos han resucitado. (Correas, 1954: 399).

Quevedo, en el tono satírico tan habitual en él, escribió esta adivinanza para «el dinero», como parte de una de sus letrillas (1981: 276):
¿Quién los jueces con pasión, sin ser ungüento hace humanos, pues untándolos las manos los ablanda el corazón ¿Quién gasta su opilación con oro y no con acero?

También Luis de Góngora (1980: 234) fue aficionado a las letrillas satíricas que contenían la expresión «qué es cosa y cosa...», tan propia de la adivinanza:
Médicos vi principales, no diré cuáles ni quiénes, que sus vidas y sus bienes hacen mil muertes y males; véndennos por muchos reales la enfermedad peligrosa; ¿qué es cosa y cosa y cosa?

A veces, la adivinanza se ha usado para escritos «a lo divino». Así, Alonso de Ledesma, en su ya citado libro Juegos de Nochesbuenas a lo divino, incluyó al final de un largo poema titulado «A la virginidad de Nuestra Señora» esta adivinanza: 
¿Qué es cosa y cosa,

que pasa por el mar y no se moja? (1613: 88)

Con ella se quiso referir a la propia virginidad de María. Sin embargo, en el devenir de la tradición popular del género adivinatorio encontramos la misma composición, o con ligeras variantes, para referirse a «la luna».

Si la literatura culta española de finales de la Edad Media y del Renacimiento prestó atención al género de las adivinanzas fue, sin duda, por la gran difusión que tenía entre las gentes de la época. La llegada de los españoles a América propició que estas composiciones se conocieran en el Nuevo Mundo, comprobándose además que existían unas composiciones muy parecidas que ya se practicaban con anterioridad, los zazaniles prehispánicos (Vid. Miaja, 2005: 117-135). De todo ello tenemos un valioso testimonio, el de Fray Bernardino de Sahagún, quien dedica el capítulo 42 del Libro Sexto de su Historia General de las cosas de Nueva España, escrita entre 1547 y 1577, a:

\begin{abstract}
Algunos çaçanjles de los muchos que usa esta gente mexicana: que son como los 'qué cosa y cosa' de nuestra lengua, percibiendo las semejanzas que existían, salvando las diferencias lingüísticas, entre los «zazaniles» cultivados por los aztecas y las adivinanzas populares españolas, conocidas entonces como los «qué cosa y cosa». (Sahagún, 1979: 201).
\end{abstract}

FINAL

De todos modos, también ha ocurrido que composiciones que nacieron del espíritu creador de excelentes escritores han pasado a formar parte de la tradición oral, transmitiéndose y perpetuándose a expensas del origen individual y concreto que tuvieron; en ese proceso, los niños, lógicamente, no han permanecido ajenos:

El éxito popular en los más variados medios sociales de romances, romancillos, jácaras, etc., de un Lope o un Quevedo, o de otros ingenios, convirtió a muchas de aquellas composiciones cultas en poesías cantadas, sujetas a los azares de la literatura de transmisión oral. (Catalán, 1970: 293).

En relación a todo ello, no es aventurado afirmar que en el Cancionero Popular Infantil perviven hoy composiciones que, con notables variantes, llevan vivas cientos de años y que, en ocasiones, en más de las que pudiéramos imaginar, han aparecido insertas en obras cultas. Al respecto, José Fradejas (1980: 9) ha señalado que:

Es cierto que pervive una poesía popular tradicional arcaica, pero no es menos cierto que, junto a ella, se ha formado otra no menos tradicional que arrancando del siglo XV y por medio de los pliegos sueltos y los cancioneros musicales llegó a impregnar hasta el teatro del Siglo de Oro y pasó — lógicamente- al pueblo. A todo lo largo y ancho del pueblo hispánico. 
Desde hace mucho tiempo es incuestionable el reconocimiento del uso que la literatura culta ha hecho de los antiguos cantares populares como material poético y que, como bien señala Margit Frenk (1984: 21-22):

Se manifiesta principalmente en el empleo de cantarcillos folclóricos como estribillos de 'villancicos' o 'canciones' que desarrollaban, en un número variable de estrofas, la idea contenida en ellos. Es decir, que se sometía a la canción popular al mismo tratamiento dado a los estribillos de carácter más literario.

\section{BIBLIOGRAFÍA CITADA}

Alonso, Dámaso y Blecua, José M. (1978). Antología de la poesía española. (Lírica de tipo tradicional). Madrid: Gredos, $2^{\mathrm{a}}$ ed.

Alonso de Ledesma (1613). Juegos de noches buenas a los divino. Madrid: Alonso Martín. (La primera edición es de 1605. Barcelona. Sebastián Cormellas).

Anónimo (1550). Cancionero General. Zaragoza: Nájera.

Anónimo (1974). Libro de Apolonio. Madrid: Castalia.

Briceño, Luis de (1626). Metodo mui facilissimo para aprender a tañer la guitarra a lo español. París.

Calvo, R. y R. Pérez (2003). Pinto, pinto, gorgorito. Retahílas, juegos, canciones y cuentos infantiles antiguos. Madrid: Sammer, $2^{\mathrm{a}}$ ed.

Caro, Rodrigo (1978). Días geniales o lúdricos. Madrid: Espasa Calpe.

Catalán, Diego (1970). Por campos del romancero. Estudio sobre la tradición oral moderna. Madrid: Gredos.

Cerrillo, Pedro C. (1994). Lírica popular española de tradición infantil. Cuenca: Ediciones de la Universidad de Castilla La Mancha. 2 vols.

Cerrillo, Pedro C. (2004). «Literatura y juego: las canciones escenificadas infantiles», Revista de Dialectología y tradiciones populares. LIX, 2, pp. 175 a 194.

Cerrillo, Pedro C. (2005). La voz de la memoria. Estudios sobre el Cancionero Popular Infantil. Cuenca: Ediciones de la UCLM.

Cervantes, Miguel de (1986). La Galatea, en Obras Completas. Vol. I. Madrid: Aguilar, $18^{\mathrm{a}}$ ed., $2^{\mathrm{a}}$ reimp.

Correas, Gonzalo (1627). Vocabulario de refranes y frases proverbiales. Salamanca: L. Combet. (Burdeos: Instituto de Estudios Ibéricos, 1967).

Cotarelo Mori, E. (1911). Colección de entremeses, loas, bailes, jácaras y mojigangas. Madrid: Biblioteca de Autores Españoles. Vol. II.

Demófilo (Machado y Álvarez, A.) (1883). «Post-scriptum»a los Cantos populares españoles de Fco. Rodríguez Marín. Sevilla: Fco. Álvarez y Cía. Vol. V, pp. 143-203.

Díez Garretas, $\mathrm{M}^{\mathrm{a}}$ J. (1983). La obra literaria de Fernando de la Torre. Valladolid: Universidad de Valladolid.

Fradejas, José (1983). «Prólogo» a Díez Garretas, Mª J. La obra literaria de Fernando de la Torre. Valladolid: Universidad de Valladolid.

Fraile, José M. (1993). «Un muestreo en la poesía tradicional de la Mancha Baja», Zahora, 33. Albacete: Diputación, pp. 13-107.

Frenk, Margit (1978). Lírica española de tipo popular. Madrid: Cátedra.

Frenk, Margit (1984). Entre folclore y literatura. México, D.F.: El Colegio de México, $2^{\mathrm{a}}$ ed.

Frenk, Margit (1987). Corpus de la antigua lírica popular hispánica. Siglos XV a XVII. Madrid: Castalia.

Frenk, Margit (2003). Nuevo corpus de la antigua lírica popular hispánica (siglos XV a XVII). México, D.F.: UNAM, Colegio de México y Fondo de Cultura Económica. 
Frenk, Margit (2006). «Supervivencia de la antigua lírica popular», en Poesía popular hispánica. 44 estudios. México, D.F.: Fondo de Cultura Económica, 2006.

Frenk, Margit y José Manuel Pedrosa (2008). «Nuevas supervivencias de canciones viejas», Revista de Literaturas Populares. VIII, 2, pp. 291-318.

Gárfer, J. L. y C. Fernández (2010). Acertijero antológico español. Madrid: Anaya.

Gil Polo (1973). Diana enamorada. Madrid: Espasa Calpe.

Góngora, Luis (1980). Letrillas, ed. de Robert Jammes. Madrid: Castalia.

Horozco, Sebastián de (1975). El Cancionero, Jack Weiner (ed.). Berna: Herberg Lang.

Jakobson, R. (1973). «Le folklore, forme spécifique de création», en Questións de Poétique. París: Seuil.

Lope de Vega, F. (1991). Los pastores de Belén, ed. de Antonio Carreño. Barcelona: PPU.

Llorca, Fernando (1998). Lo que saben los niños. Valencia: Prometeo.

Mal Lara, Juan de (1958). Philosophia vulgar..., ed. de A. Vilanova. Barcelona. Vol. I.

Masera, Mariana (1994). «Las nanas, ¿una canción femenina?», Revista de dialectología y tradiciones populares. XLIX, 1, pp. 199-219.

Masera, Mariana (2010). «Que salga la dama que la quiero ver bailar: bailes y poesía en las rimas infantiles del cancionero hispánico», en Pedro C. Cerrillo y César Sánchez. Tradición y modernidad de la literatura oral. Cuenca: Ediciones de la UCLM, pp. 85-111.

Mercado, Tomás de (1977). Suma de tratos y contratos. Madrid: Instituto de Estudios fiscales.

Miaja, Ma Teresa (2005). «De los zazaniles y quisicosas en Fray Bernardino de Sahagún, a la adivinanza actual en México», en VV. AA. Prolija memoria. Estudios de cultura virreinal. Vol. 2. México: Facultad de Filosofía y Letras, UNAM y Universidad del Claustro de Sor Juana, pp. 117-135.

Milán, Luis de (1874). El cortesano. Madrid: Imprenta Aribau.

Mosquera de Figueroa, A. (1955). Obras. I. Madrid: Real Academia Española de la Lengua.

Nebrija, Antonio (1492). Gramática castellana. Salamanca. Galindo y Ortiz. (Madrid: Junta del Centenario, 1946).

Pedrosa, José Manuel (2000). Tradición oral y escrituras poéticas en los Siglos de Oro. Oiartzun: Sendoa.

Pelegrín, Ana (1996). La flor de la maravilla. Juegos, recreos, retahílas. Madrid: Fundación Germán Sánchez Ruipérez.

Pérez de Herrera (1618). Proverbios morales y consejos cristianos. Madrid.

Piñero, Pedro M. (2010). La niña y el mar. Formas, temas y motivos tradicionales en el cancionero popular hispánico. Madrid: Iberoamericana Vervuert.

Quevedo, Francisco de (1981). Poesía varia, ed. de James O. Crosby. Madrid: Cátedra.

Rodríguez Marín, F. (1882-83). Cantos populares españoles. Sevilla: Fco. Álvarez y Cía. 5 vols. (Madrid: Atlas, 1981).

Rodríguez Marín, F. (1932). Pasatiempo folklórico. Varios juegos infantiles del siglo XVI. Madrid: Tipografía de Archivos.

Rodríguez Moñino, A. y D. Devoto (1954). Ed. Cancionero llamado flor de enamorados. Madrid: Castalia.

Sahagún, Fray Bernardino de (1979). Historia General de las cosas de Nueva España, facsimilar del Manuscrito 218-20 de la Colección Palatina de la Biblioteca Medicea Laurenziana (Códice Florentino). Vol. II. México, D.F.: Archivo General de la Nación.

Sousa Viterbo (1901). A livraría real. Lisboa: Typ. da Academia.

Spirito, Lorenzo (1991). Libro de suertes. Valencia: Jorge Costilla, 1515. Salamanca: Europa. Timoneda, Juan de (1954). Cancionero llamado flor de enamorados. Ed. de Rodríguez Moñino y Daniel Devoto. Madrid: Castalia. 